\title{
A Sustainable Model? University Presidents Assess the Costs and Financing of Intercollegiate Athletics
}

\author{
Rick Hesel \\ Art \& Science Group, LLC \\ Amy Perko ${ }^{1}$ \\ Knight Commission on Intercollegiate Athletics
}

\begin{abstract}
The sustainability of the rapidly growing costs of intercollegiate athletics at Football Bowl Series (formerly Division 1A) universities, long a serious concern of the NCAA and Knight Commission on Intercollegiate Athletics, has been exacerbated by the recent economic downturn and become a source of increasing scrutiny by public officials, university leadership, and the media. To gain a better understanding of FBS university presidents' views on this matter, the Knight Commission conducted quantitative and qualitative research with these presidents. In total, 95 of the 119 FBS presidents completed initial 10-min quantitative telephone surveys, with 22 of the presidents subsequently participating in in-depth qualitative interviews.
\end{abstract}

Presidents were asked to assess the benefits that intercollegiate athletics might provide FBS universities; the sustainability of trends in athletics revenues and expenses; the short and long term effects of the recession on athletics; and, policy changes presidents might consider to impact athletics finances.

The presidents' responses to the quantitative survey were analyzed using a variety of variables including athletic budget, football and basketball coaches' compensation, athletic success, undergraduate enrollment, and presidential tenure.

Less than a quarter of presidents believe athletics programs in the FBS are sustainable in their current form considering recent trends and the economic outlook. While presidents recognize the need for reform, there is a lack of clear consensus about the best way to effect change. A majority believe institutions must act collaboratively to address escalating costs. Coaches' salaries are viewed as the greatest impediment to sustainability but those costs are difficult to control. More than $80 \%$ of presidents believe greater financial transparency for athletics costs is needed.

Hesel is Principal, Art \& Science Group, LLC, Baltimore, MD. Perko is the Executive Director, Knight Commission on Intercollegiate Athletics. 
Note: The complete report of the Quantitative and Qualitative Results from the Survey of Football Bowl Subdivision University Presidents on the Costs and Financing of Intercollegiate Athletics is accessible at www.knightcommission.org.

The Knight Commission on Intercollegiate Athletics recently celebrated the 20th anniversary of its founding in October 1989. Throughout its existence, the Knight Commission has been an independent voice advocating for the alignment of athletics programs with their universities' educational missions. Although it does not hold official authority over the various organizations involved in the administration of intercollegiate athletics, many of the Commission's recommendations have been adopted by the National Collegiate Athletic Association (NCAA), institutional boards of trustees, and other important governing bodies.

The Commission's landmark 1991 report, Keeping Faith with the StudentAthlete: A New Model for Intercollegiate Athletics, proposed a "one-plus-three" model for intercollegiate athletics - presidential control directed toward academic integrity, fiscal integrity, and an independent certification process to verify that integrity (Knight Commission on Intercollegiate Athletics, 1991). Indeed, the "oneplus-three" model provided a roadmap that the NCAA and university presidents used to implement academic and governance reforms over the past two decades.

Despite the progress made with presidential governance and academic reforms, the escalating costs of competing in big-time intercollegiate sports, especially at NCAA Football Bowl Subdivision (FBS, formerly Division IA) institutions, have remained an intractable problem. As the late NCAA President Myles Brand (2008) observed in his December 2008 NCAA President's Report, "athletics spending has increased in recent years at a pace that ultimately is unsustainable" (p.1).

In the January 2009 State of the Association speech that was written by Brand (2009) and delivered by NCAA Vice President Wallace Renfro, several statistics were listed that provided further evidence of the growing financial dilemma:

“...universities are accelerating their spending on college sports. For more than a decade, the rate of increase in athletics' expenditures in Division I has exceeded the rate of increase in the general university budgets by a factor of three to four" (pg. 3).

"Revenues for athletics tend to increase faster than the general university budget. Yet, in recent years, they have not, on average, kept pace with expenditures" (pg. 3).

“...just six athletics programs in Division I have been in the black for each of the past five years" (pg. 3).

More recently, in the 2009 edition of the NCAA revenues and expenses report, Fulks (2009) found that roughly $80 \%$ of the FBS programs averaged a net operating deficit of nearly \$10 million for the 2007-08 fiscal year.

The Knight Commission's own analysis of NCAA data presented in the Commission's College Sports 101 report (2009) revealed that at most institutions in the FBS, athletics budgets are rising more quickly than academic budgets, on average, and institutional subsidies to athletics are rising more quickly than both. 
These circumstances made the need for a new study addressing the benefits and costs of intercollegiate athletics especially urgent. Throughout its existence the Knight Commission has relied on presidential opinions to shape the Commission's agenda and the research described herein follows that framework.

Art \& Science Group conducted the research for the Knight Commission so that the Commission could gather critical information to share with all leaders responsible for managing these complex issues during these particularly challenging economic times. The Commission plans to consider the research findings and other data to inform recommendations it intends to make later this year in a major report.

\section{Research Design and Methodology}

The research with the 119 FBS university presidents was completed in two stages. The first stage, consisting of quantitative research, was conducted from March 18 to May 20, 2009. Ten-minute telephone interviews were completed with 95 of the 119 FBS university presidents, a participation rate of nearly $80 \%$, extraordinarily high for a research study with any leadership population, but especially for one involving presidents of major universities. (It should be noted that during the 2009-10 academic year, one additional university has become an active FBS institution, bringing the total number to 120).

The second phase consisted of qualitative telephone interviews with FBS presidents who had completed a quantitative interview. These presidents agreed to participate in a follow-up discussion exploring in greater depth the questions covered in the quantitative research as well as other issues suggested by preliminary findings. Of the 95 presidents who completed quantitative interviews, 67 (71\%) volunteered to participate in a follow-up interview. Twenty-two interviews (roughly the number designated in the study design) were completed with this group, with the interviews lasting an average of nearly 45 minutes. The interviews were conducted between June 10 and July 8, 2009.

Of the 22 presidents interviewed, eight were current or former members of the NCAA Board of Directors at the time of the interview, and 12 of the respondents had at least six years of experience as a president at any FBS institution. The respondents tended to be from public institutions (18 of 22), and the athletics budgets they supervised are roughly equally spread across low (less than $\$ 23,208,000$ ), middle $(\$ 23,208,000$ to $\$ 45,990,000)$, and high $(\$ 45,990,000$ or higher) ranges. Finally, as presidents from equity institutions have more control over NCAA policy matters for the entire division, a greater proportion of these presidents (14 of 22, or nearly two-thirds) were included in the qualitative phase of the research.

The extraordinarily high participation rates of FBS presidents as well as the considerable time and interest they were willing to devote to the research strongly suggest that issues and concerns regarding the financing of intercollegiate athletics are viewed as matters of profound consequence for the leadership of these universities, which represent many of the country's most distinguished institutions of higher learning.

The high percentage of FBS presidents who completed interviews also ensures that the sample and the research findings accurately represent the views of presidents 
across a number of important variables, including athletic conference, region of the country, and levels of athletic success. For example, nearly $80 \%$ of the institutions represented in either the 2009 top 25 football or men's basketball media polls are included. In addition, at least two-thirds of the members of each of the 11 FBS conferences are included.

Another key variable used in the analysis was an institution's membership in an equity or nonequity conference. Equity conferences, so called because conference champions receive automatic bids to the highly lucrative Bowl Championship Series (BCS), include the Atlantic Coast Conference, Big Ten Conference, Big XII Conference, Pacific 10 Conference, Big East Conference, and Southeastern Conference. The University of Notre Dame is included in this category given their preferential BCS qualification status.

Equity conferences have the most lucrative television contracts and have access to other substantial financial benefits not enjoyed by nonequity conferences. The independent military academies are included in the nonequity category. The portion of equity (54\%) and nonequity (46\%) institutions in the quantitative sample mirrors the actual portions in the FBS. (For ease of reference, in this paper, presidents of institutions in equity conferences are referred to as "equity presidents," those of institutions in nonequity conferences as "non-equity presidents." Similarly, institutions in equity conferences are referred to as "equity institutions," those of institutions in nonequity conferences as "non-equity institutions.")

\section{Summary of Findings}

The following provides a summary of key findings from the quantitative and qualitative research.

\section{Sustainability}

Based on findings from the quantitative and qualitative research, it is clear that the question for a majority of presidents of equity and nonequity institutions alike is not whether the current financial model of college athletics is sustainable but, given the forces at work, how long it can be sustained.

In terms of their own institutions, two-thirds of FBS presidents expressed confidence that, considering current trends in athletics revenues and expenses, athletics operations are sustainable in their current form (see Figure 1). However, this confidence was not extended to other institutions in their conferences or to the FBS as a whole. And, even in the context of their own programs, nearly half of all respondents (48\%) expressed concern that the current outlook will affect the number of varsity sports their institution can retain in the future (see Figure 2).

In the qualitative research, respondents voiced broad concerns regarding the sustainability of all athletics programs in the face of what a number of presidents described in the qualitative interviews as an "arms race" that is driving up costs for athletics programs and creating tensions that cannot be clearly measured in other areas. These concerns were shared by a majority of those presidents interviewed regardless of their athletics programs' financial outlook. 


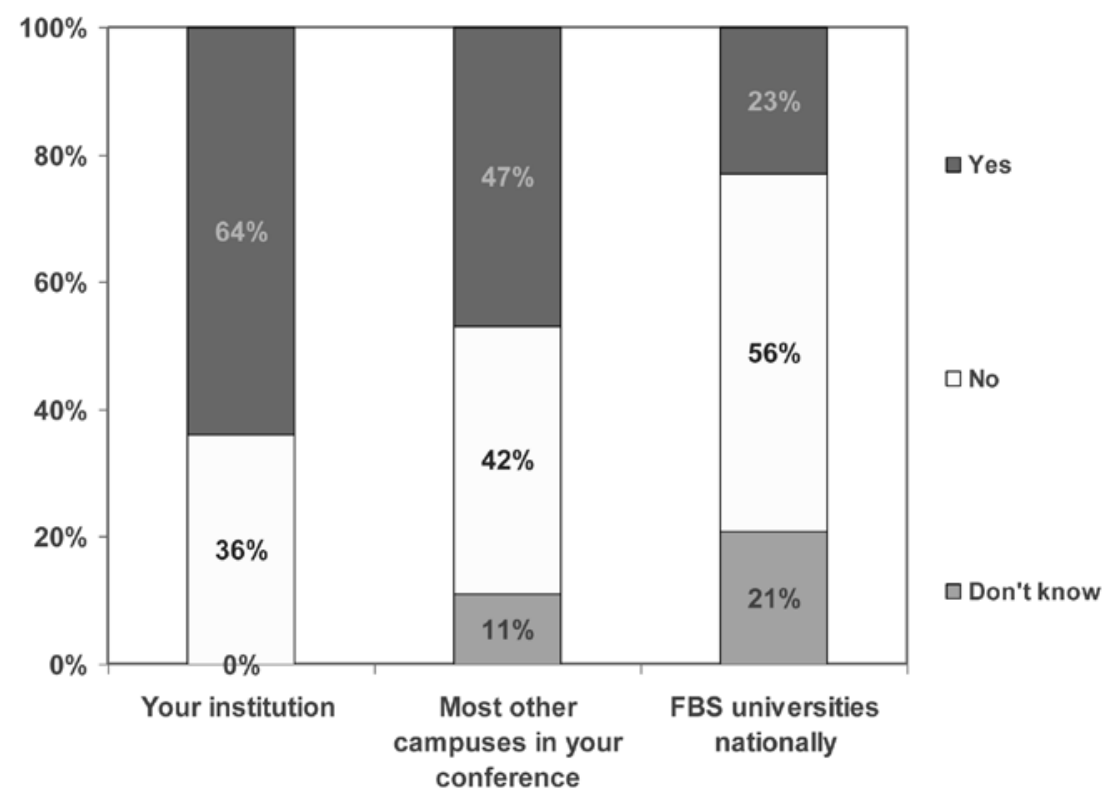

Figure 1 - Given the trends you see in revenues and expenses, including both operating and capital expenses, do you believe athletics operations are sustainable in their current form at. .

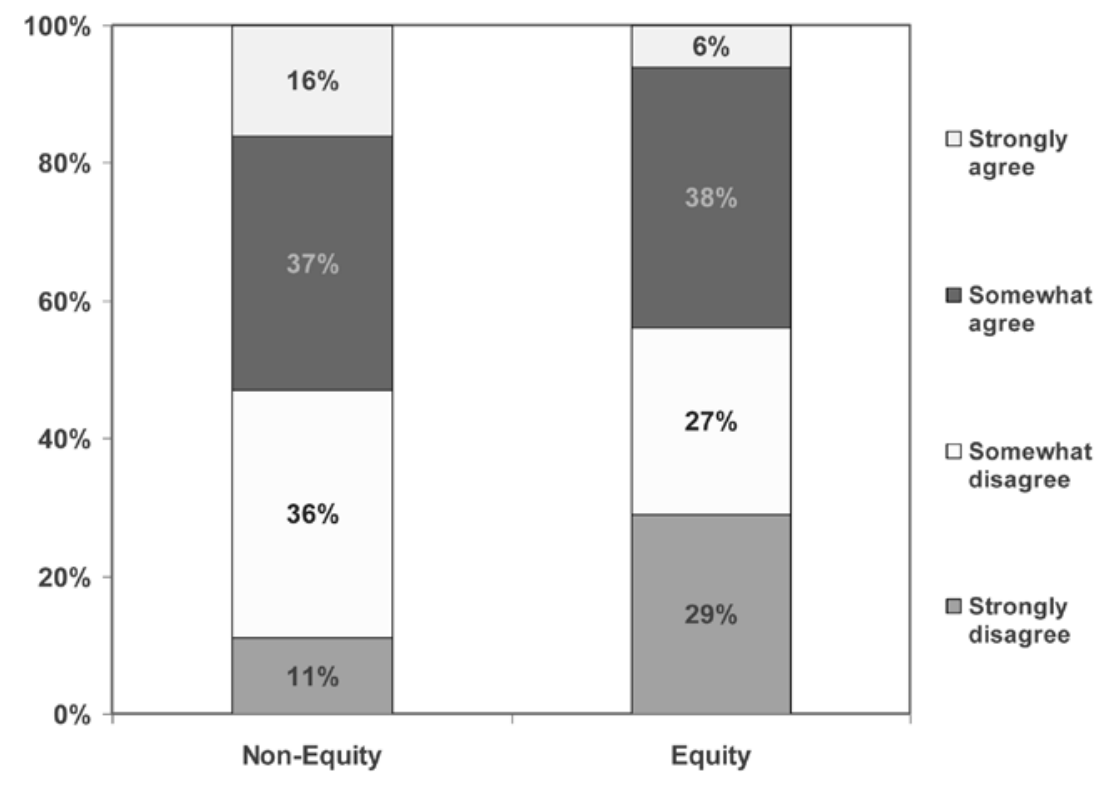

Figure 2 - Agreement with statements about college athletics: You are concerned that the current economic outlook will impact the number of varsity sports your institution can retain in the future. . 
Issues identified by presidents as key factors in the accelerating costs of competing at the FBS level include the following:

- Increases in coaches' salaries and privileges as well as the increasing costs of the expanding number of sports-specific personnel.

- Commercialization, including TV contracts and other corporate interests which have injected substantial revenue into intercollegiate athletics.

- Costs of building more and better appointed facilities.

Presidents also identified a number of challenges associated with the increasing costs of FBS participation, chief among them:

- Difficulties in balancing the athletic budget and keeping costs under control. This pressure is increasingly felt by nonequity presidents, two-thirds of whom reported a concern about the proportion of institutional resources used to fund athletics on their campus.

- Insidious and growing cultural divide between academics and athletics in which athletics is in an increasingly privileged position. This has created mounting tensions and concerns about conflicts with institutional mission and values.

- Growing imbalance between the "haves and have-nots" both within equity conferences and between equity and nonequity institutions. Presidents of less competitive institutions (the "have-nots") feel that their programs are being unfairly exploited.

- Concern that competitive and financial pressures created by the "arms race" are having an increasingly negative impact on student athletes.

- Challenges for some programs to continue to be competitive or even to maintain their Division I status.

\section{Implications of Increases in Coaches' Salaries and Sports- Specific Personnel}

When asked about salaries across FBS institutions nationally, an overwhelming majority of FBS presidents ( $85 \%$ ) indicated they felt compensation for football and basketball coaches was excessive in the context of higher education (see Figures 3 and 4).

The qualitative research suggests that presidents saw the issue of coaches' salaries as a key contributor to the "arms race" in intercollegiate athletics. Coaches' salaries are seen as the greatest impediment to sustainability. In addition to placing strains on the institutional finances, increases in coaches' salaries and, to a lesser extent, increases in the numbers of other sports-specific personnel required for the athletic enterprise in the FBS were seen to create a public-relations challenge with regard to other internal and external university constituencies.

Presidents were pessimistic about their ability to control these costs. A majority $(56 \%)$ felt that as the use of private monies to compensate coaches has increased, their control over coaches' salaries has decreased (see Figure 5). A majority of presidents did not support attempts to change federal legislation to allow some level of control on coaching staff salaries. This seemed to be tied to presidents' skepticism about the political possibility of intercollegiate athletics being granted an exemption from antitrust legislation. 


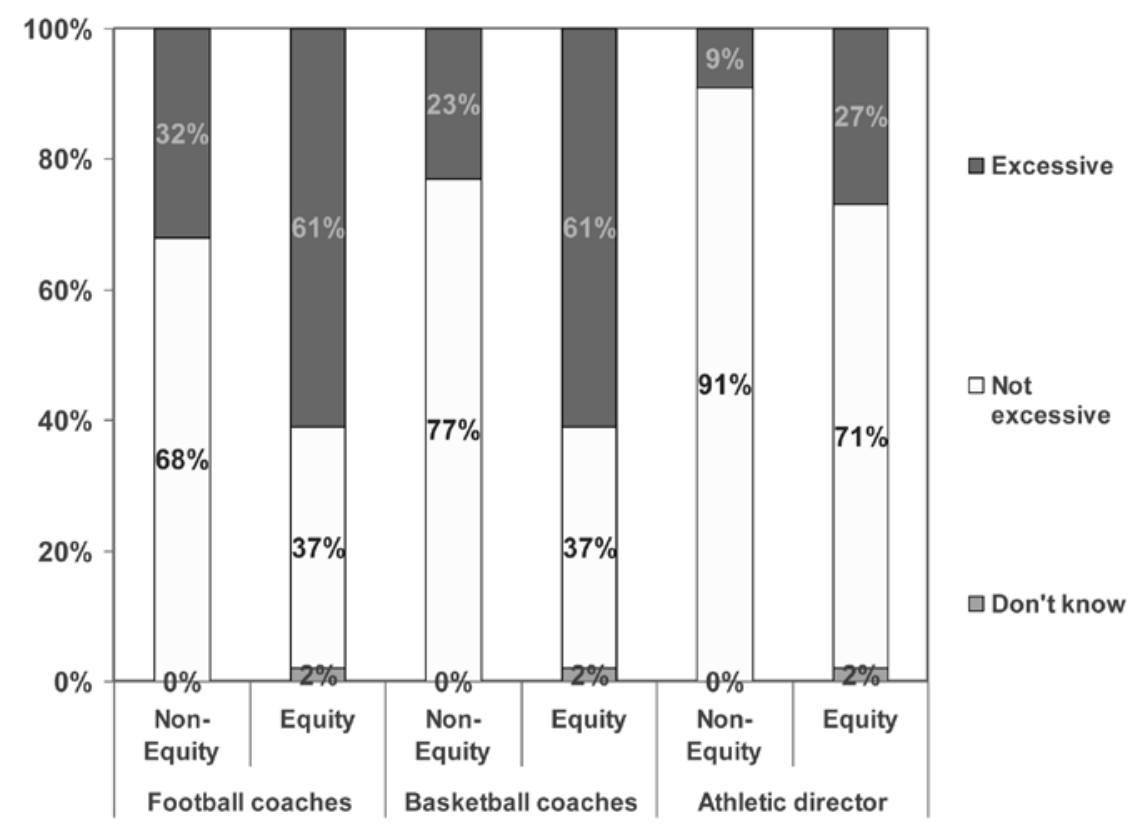

Figure 3 - Feel the total compensation for athletic positions at your institution is excessive in the context of higher education?

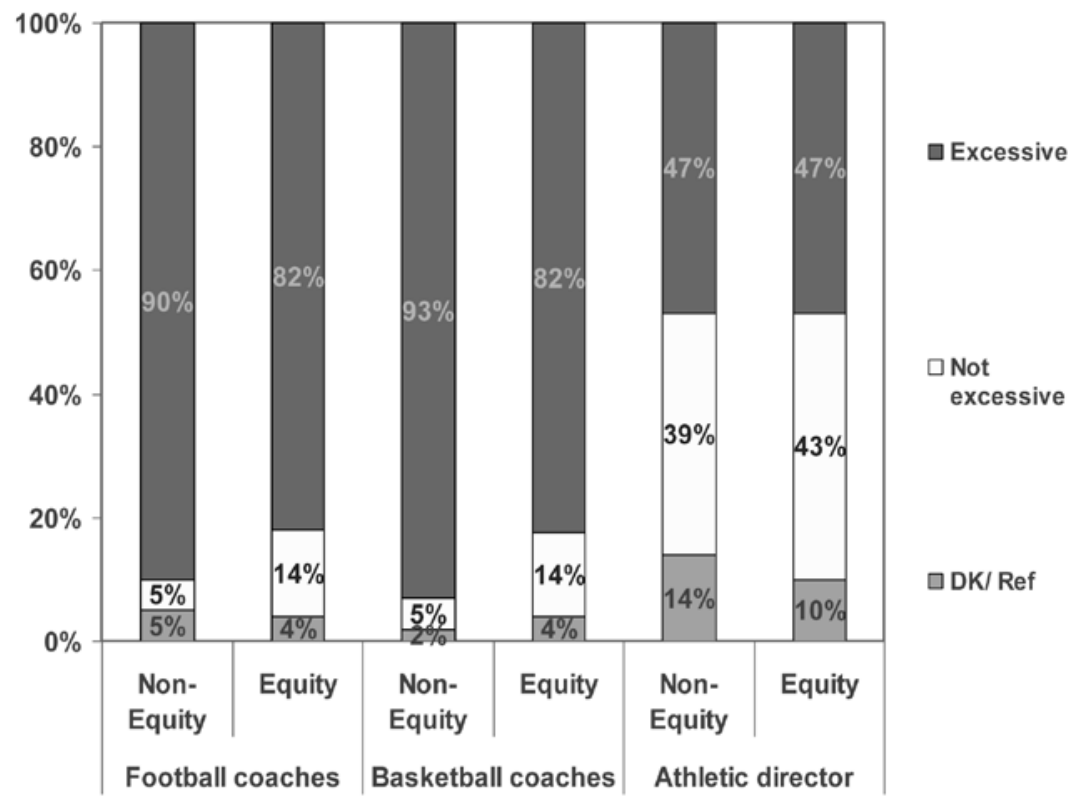

Figure 4 - Feel the total compensation for athletic positions at other FBS institutions is excessive in the context of higher education? 


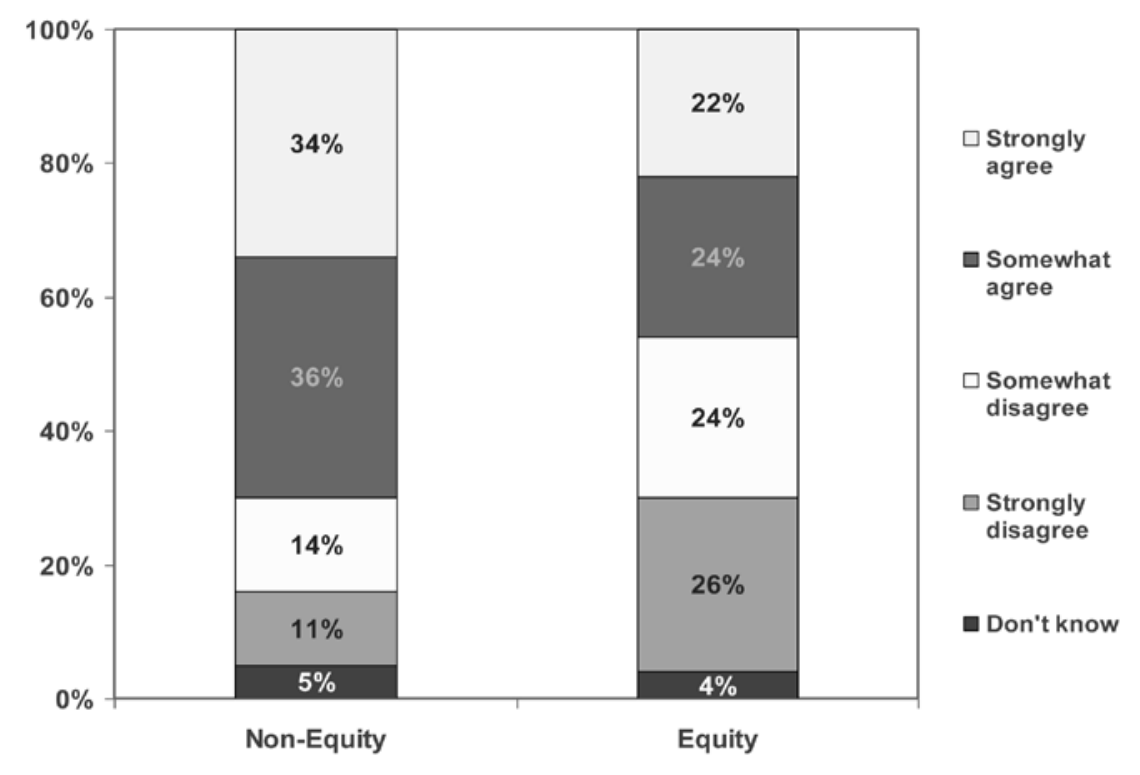

Figure 5 - Agreement with statements about athletics: The increasing degree to which private monies are used to fund football and basketball coaches' salaries has reduced presidential authority over these decisions at FBS institutions. . .

\section{Budget Pressures Produced by Increasing Costs of Operating Successful Athletic Programs}

Quantitative and qualitative results suggest that the increasing costs of operating successful athletics programs, especially in the current economic climate, present serious challenges to FBS presidents. For presidents of nonequity institutions, which operate with far less athletics revenue, these challenges are especially daunting.

Most presidents reported making athletics budget cuts in the most recently completed fiscal year, and a significant number anticipate continuing declines in revenues through next year. A majority of presidents $(62 \%)$ believed the recession has affected athletics budgets at the same level as other units of their university. Key factors associated with the recession's impact on FBS campuses included the following:

- The recession affected both public and private funding sources.

- Most universities athletics budgets reductions equated roughly proportionally to cuts being made in other units of the institution.

- Presidents have largely delegated responsibility for determining details of budget cuts to their Athletics Director.

Despite widespread concern over financial stresses created by the "arms race" and exacerbated by the recession, the most common sentiment expressed by presidents regarding current levels of spending was their desire to increase revenue rather than opt out of the system or push for systemic change. 


\section{Cross-Institutional Benefits of Successful Athletics Programs}

Despite the concerns expressed by presidents regarding the pressures placed on their institution through its participation in the FBS, competing at this level is seen to carry considerable financial as well as less tangible benefits. Although a number of presidents are aware of scholarly research questioning the relationship between big-time athletics and nonathletic benefits, personal experience plays a much more powerful role in defining presidents' attitudes toward athletics than do the results of these studies (see Figure 6).

A significant majority of FBS presidents believed that athletics success provides substantial benefits to their institutions. These include tangible benefits such as increasing applications, quality of the student body, and donations to the university. Presidents also saw indirect benefits stemming from athletics success, including enhancing school spirit and raising the profile of the institution with regard to the general public, public officials, and other university presidents. Some of these latter benefits were seen to provide leverage for more concrete benefits such as helping to generate higher levels of giving and helping to attract more and better qualified students.

Presidents did not view fundraising for athletics and academics a zero-sum game, in which financial gains for athletics programs were made at the expense of the academic side of the house. Despite research suggesting that athletics are taking a larger share of donations, $80 \%$ of presidents expressed the belief that athletics fundraising does not take from the same pool of money that would otherwise go to general university fundraising.

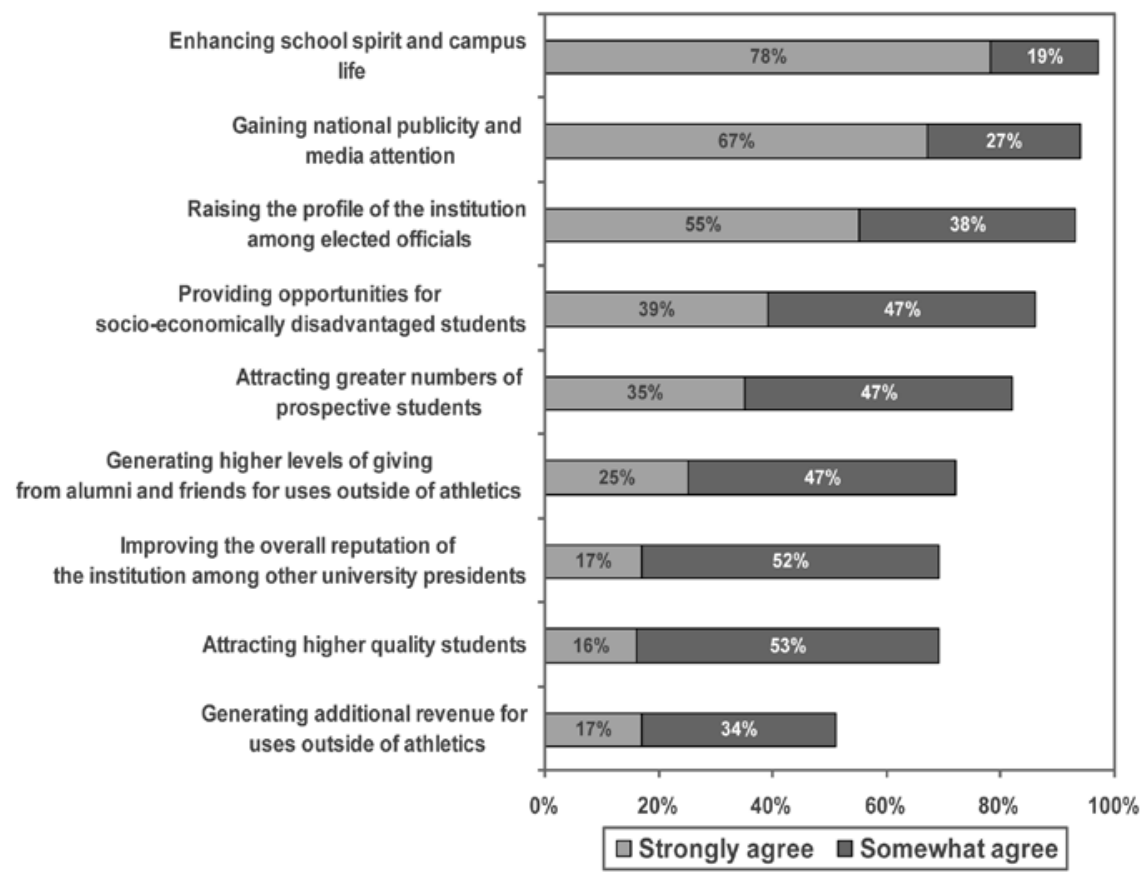

Figure 6 - Agreement with statements about intercollegiate athletics programs. . . 


\section{Transparency}

With regard to the financial information currently available, almost every president $(95 \%)$ agreed that they were confident in the accuracy of the financial information they receive from their athletics departments, with a vast majority of these $(82 \%)$ being very confident. Presidents expressed lower levels of confidence regarding the financial information reported by their peer institutions $(61 \%$ were "somewhat" confident this information was accurate).

Their confidence in data currently available notwithstanding, nearly 8 in 10 presidents agreed that greater transparency of athletics operating and capital costs is needed. Many presidents, particularly those at public universities already required to comply with state standards regarding financial data, were convinced that their programs currently practice transparency, although some acknowledged that not all information is readily available. Furthermore, the interviews revealed a lack of consensus regarding what constitutes transparency and recognition that it is possible to game the system regarding the nature and appearance of financial data. That said, generally, presidents agreed that standards should be set regarding reporting of individual institutional data so that measures are consistent.

Nearly 9 out of 10 FBS presidents have reviewed the NCAA financial dashboard indicators for their institutions. The NCAA is viewed as a key player in providing even greater transparency, particularly in a way that provides a reliable basis for cross-institutional and conference comparisons that would be available to the media and general public.

\section{The Dilemma of Reform}

It is clear from the quantitative and qualitative research that presidents recognize the need for reform; few, however, are sanguine about the possibilities for positive change. What is striking in many of the findings is the lack of any clear idea of the best way to effect change or the most appropriate entity to move reform efforts forward.

While the quantitative research revealed strong presidential support for studies of policy changes regarding a number of concerns, such as the number of coaches and athletic contests, the qualitative research revealed a sense of individual powerlessness to effect the kind of change that is needed at the conference and national levels to contain the athletics arms race and address critical issues regarding sustainability, such as rapidly escalating coaches' salaries. The quantitative research also showed that a high percentage of presidents who believed that sustainability is problematic for their own institution or for their conference or the FBS as a whole believed that sweeping change is necessary across the FBS.

In sum, presidents would like serious change but don't see themselves as the force for the changes needed, nor have they identified an alternative force they believe could be effective.

While serious problems are recognized, beyond limited actions they can take on their own campuses, presidents were at a loss to describe solutions that will address the broader FBS problems. The following were chief among their concerns:

- Presidents believed they have limited power to effect change on their own campuses regarding athletics financing and the larger problems it has created, much less for the FBS as a whole. Indeed, nearly three-quarters interviewed in the quantitative 
research believed that athletics presents unique challenges as compared with schools, divisions, or other parts of the university when trying to control costs.

- While antitrust exemption and other political solutions have some appeal, these were seen as political impossibilities by many FBS presidents.

- Outside sources of income for intercollegiate athletics, such as extremely lucrative television contracts, have diminished presidents' authority over athletics and their ability to influence reform.

- While there was some satisfaction with the steps taken by their conferences, there was also serious doubt that the conferences will make decisions or take actions that are against the self-interest of the most successful conference institutions.

A majority of presidents interviewed in the quantitative research favored studying the following policy initiatives to explore how these might help control costs and make FBS athletics more sustainable (see Figure 7):

- Reduce the number of coaches and sports-specific personnel for revenueproducing sports (supported by roughly two-thirds of presidents).

- Reduce the number of contests for nonrevenue producing sports (supported by roughly two-thirds of presidents).

- Change BCS (supported by $62 \%$ of presidents) and NCAA revenue distribution policies (supported by $53 \%$ of presidents).

- Reduce the level of financial commitment required for FBS membership (supported by $60 \%$ of presidents).

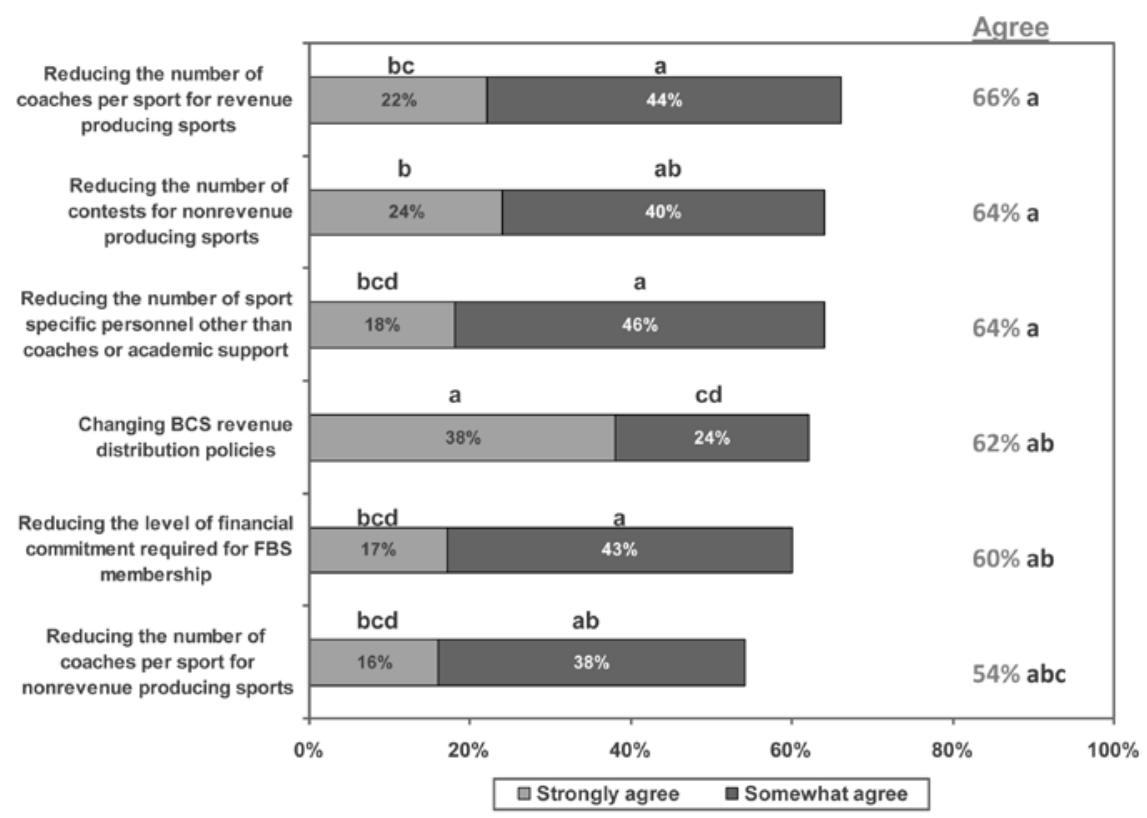

Figure 7 - Agreement with giving priority to studying the following policy changes. . . 


\section{Discussion of Key Findings}

Three of the major issues identified in the research were the unsustainable financial trends for the FBS as a whole; the perceived limited power of presidents to address the cost issues individually; and, the agreement that greater transparency of athletics operating and capital costs is needed.

A majority of the presidents supported collective efforts to address what they perceived as trends that are not sustainable for the FBS as a whole. Indeed, four out of five presidents who believed sustainability is problematic at their own institution felt that wider sweeping action is required across all FBS institutions to achieve sustainability. A similar number of presidents who believed that athletics operations are sustainable in their current form at their own institutions but not at most other campuses in their conference also felt that wider sweeping action will be required.

The desire to act collectively to address these issues is influenced by the opinion shared by three-quarters of the respondents that athletics, as compared with other parts of the university, presents unique challenges with regard to controlling costs (see Figure 8).

Not surprisingly, differences of opinion about the sustainability of their own programs emerge when examining the responses of presidents of equity and nonequity institutions (see Figure 9). Presidents of equity institutions are significantly more likely to believe that the current situation is sustainable at their own institutions ( $76 \%$ for equity vs. $50 \%$ for nonequity presidents).

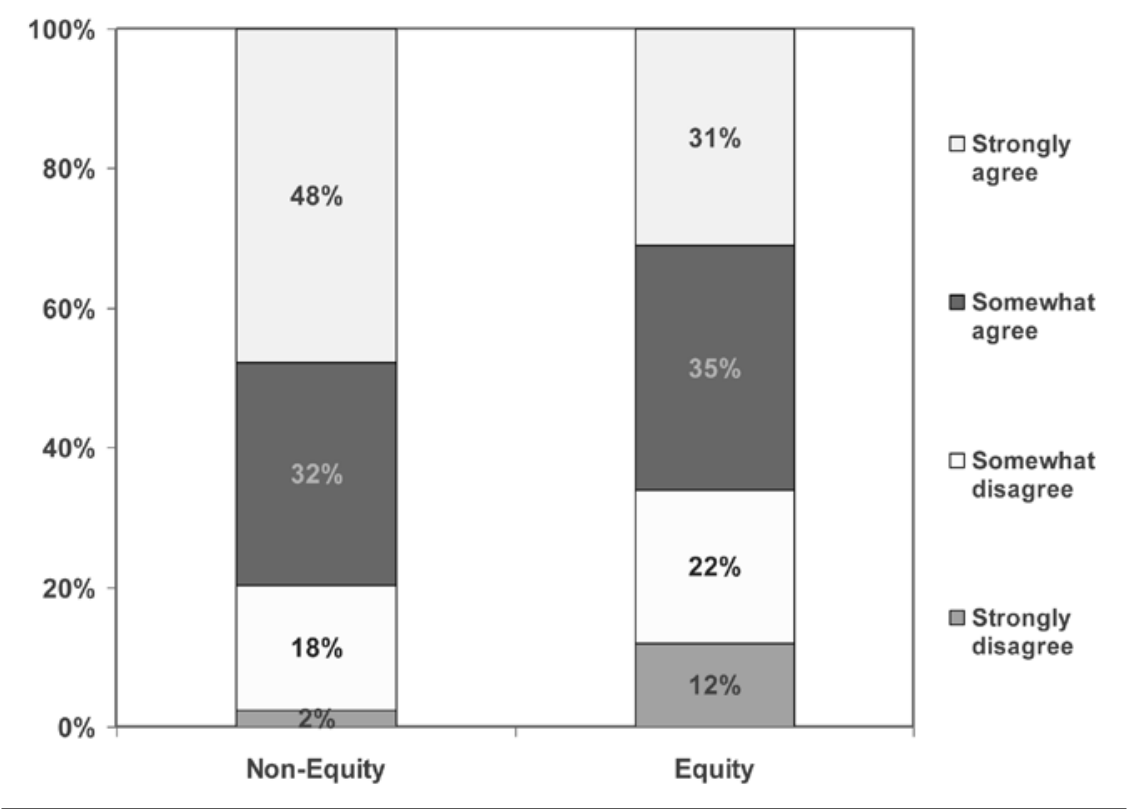

Figure 8 - Agreement with statements about college athletics: When trying to control costs, athletics presents unique challenges as compared with schools, divisions, or other parts of the university. . 


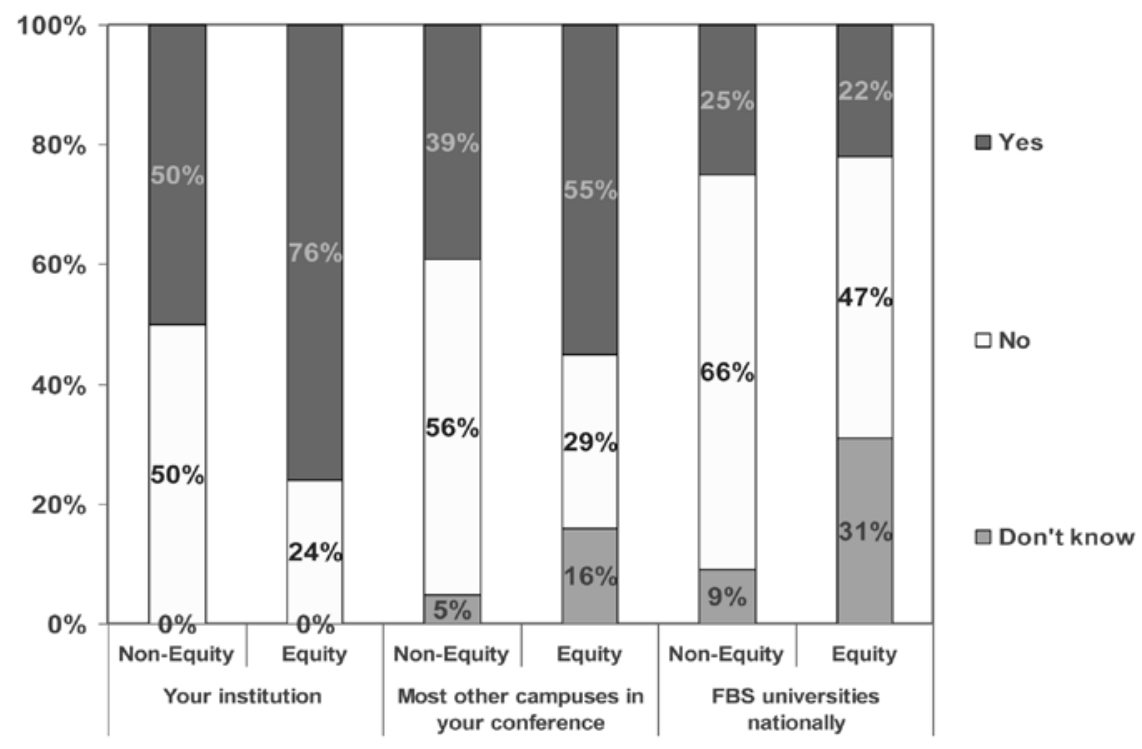

Figure 9 - Given the trends you see in revenues and expenses, including both operating and capital expenses, do you believe that athletics operations are sustainable in their current form at. . .

The financial pressures of participation in the FBS are more keenly felt by presidents of nonequity institutions, two-thirds of who were concerned about the proportion of institutional resources used to support athletics (see Figure 10). Only a quarter of equity presidents expressed such concern.

NCAA data presented in the Commission's College Sports 101 report (Knight Commission on Intercollegiate Athletics, 2009) illustrates why presidents at institutions with greater reliance on institutional subsidies have more significant concerns about the sustainability of their athletics programs (see Figure 11). When the 119 FBS institutions are divided into deciles and ranked by total athletics budgets, the institutions represented in the bottom five deciles (those with the smaller budgets) show a reliance on institutional subsidies that range from a third to half of the total athletics budget, on average.

In the qualitative interviews, several presidents of equity-conference universities with national success in football and basketball were quite vocal about the challenges all institutions face with regard to sustainability over the long run. A president of a university with a particularly successful equity program warned,

We'll get to the point where we literally can't do it. And we're one of the rich schools. TV contracts won't continue to grow. The money will cut itself off. We're going the way of NASCAR, which priced itself out of its market by building too many training facilities and the like. 


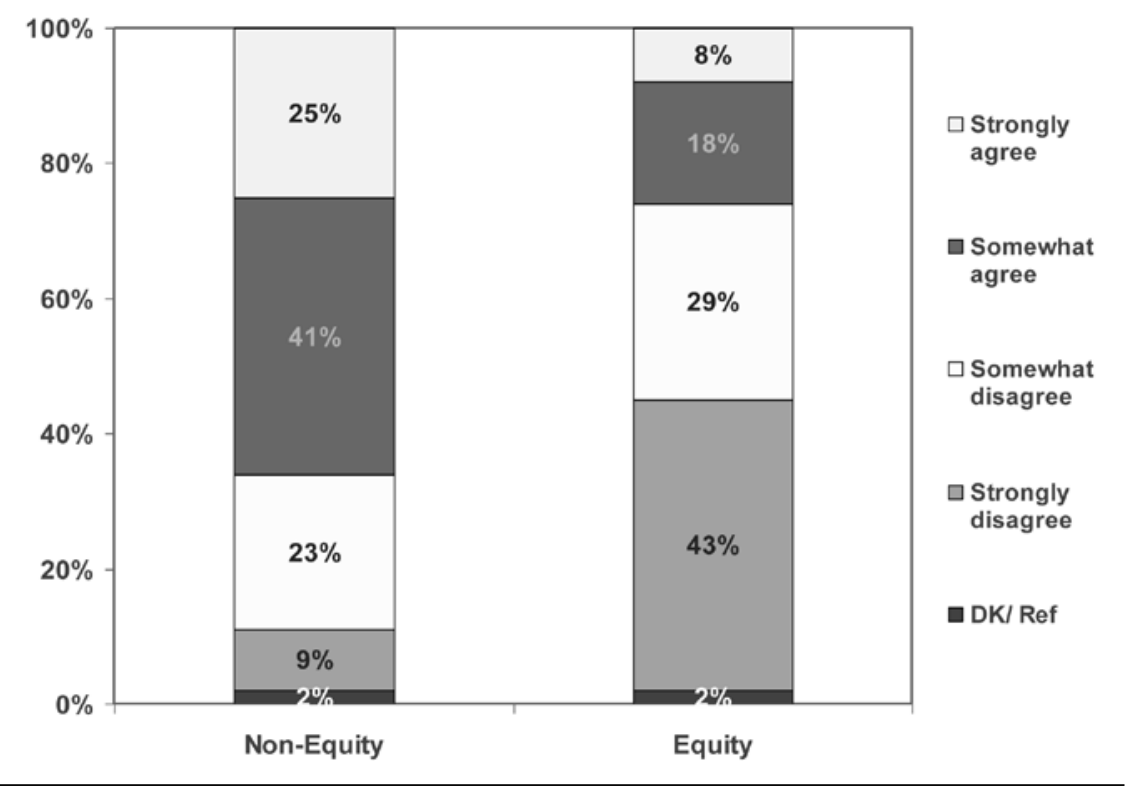

Figure 10 - Agreement with statements about college athletics: You are concerned about the proportion of allocated revenue or institutional resources, such as student fees or institutional transfers, used to fund athletics on your campus. . .

An equity president leading an institution with relatively few financial problems - it operates in a highly successful conference and has a balanced athletic budget-expressed concerns about his institution's ability to stay financially healthy over the long term:

It seems sustainable at the moment, but it is dependent on so many thingsgate receipts and the success of our teams... There are so many variables, so I wouldn't want to blithely say it's sustainable.

This president went on to add,

Everybody who says they are doing okay is scraping by and they are driving up the costs and the pressure on athletics. There are campuses on which the subsidy to athletics is significant and raises some questions about having to make cuts in other areas such as academics and administrative staff because athletics is subsidized.

Perhaps the most pointed assessment of the situation was provided by another president of an equity institution who went further, claiming that not only is the current situation unsustainable but a number of other presidents are simply in denial about the depth of the problem: 


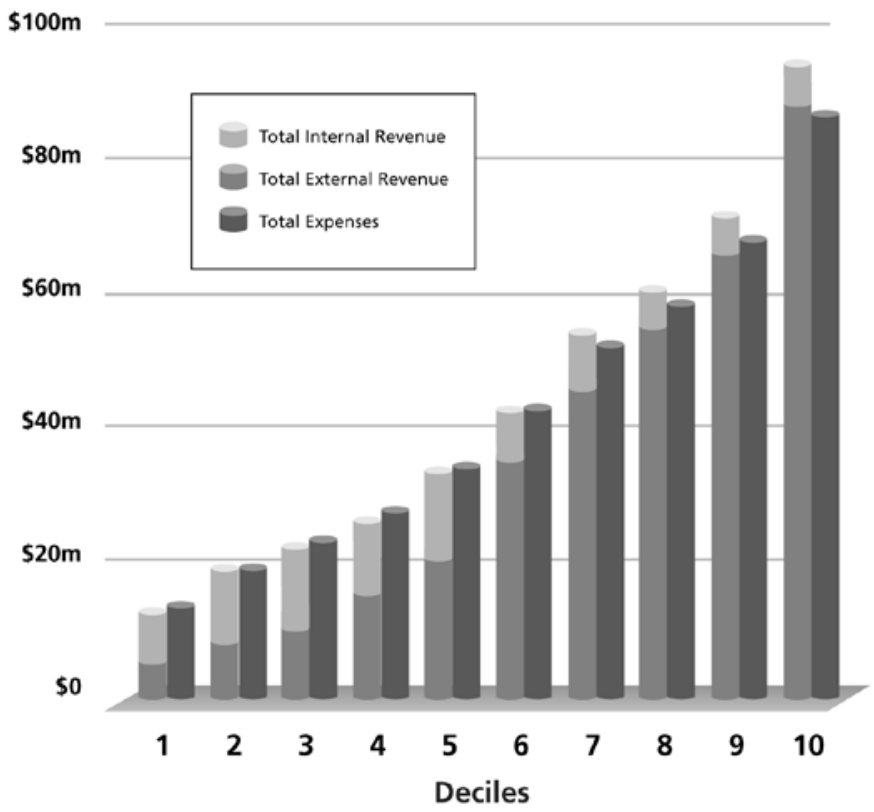

Figure 11 - This figure from the Knight Commission's College Sports 101 report shows operating deficits for most programs, operating surplus for a few. The average revenue (internal and external) is compared with the average operating expenses using NCAA data from 2006 to 07. Note: In this figure, external or "generated" revenue consists of funds the athletics program earned from external sources, such as ticket sales and broadcast revenues. Internal or "allocated" revenue consists of student fees, transfers from general fund sources, state appropriations, and other sources internal to the institution. Deciles are ranked by total athletics operating expenses as represented in Figure 12. Operating expenses do not include annual debt service. Overall debt is illustrated in Figure 13. Data source: NCAA, 2006-07 fiscal year.

I think there are a lot of heads in the sand. A lot of presidents don't get as deeply into it as they need to. There are a lot of money games played in terms of how you account for things in athletics (facilities maintenance, etc.). There are a lot of places even at the FBS level that are running headlong over a cliff.

The level of presidents' concerns over escalating athletics costs is expressed in the use of the "arms race" phrase to characterize the current situation by around half of those interviewed. When asked about his greatest concerns regarding financing intercollegiate athletics at his campus, one president bluntly stated: "The arms race." As he went on to explain,

there are pressures to do more in order to compete with other conferences. We've doubled athletics expenditures in the last five-year period. That's unchecked and starts to challenge the integrity of the enterprise.

Other presidents used similar language in expressing their concerns: 
The pressure to join the arms race is a real concern, especially for very successful mid-majors. How do you keep up with the big dogs? Of course the coaches tell us all it takes is money, which is in short supply around here these days.

The problem is, it's such big money. It's an arms race that's self-perpetuating.

The arms race in coaches' salaries and facilities is going to create all kinds of problems, particularly when you see coaches paid \$4 million.

The so-called arms race in college athletics and the kind of money that is spent on facilities and accoutrements is a real arms race.

One of the consequences of this "arms race" is a widening gulf between the "haves and have-nots." In other words, those programs that succeed and enjoy high levels of revenue as a consequence ("haves") and less successful programs that do not receive the same level of financial benefit ("have-nots") yet incur the high costs of competition.

Data in Knight Commission's College Sports 101 report (Knight Commission on Intercollegiate Athletics, 2009) highlight these growing disparities (see Figures 12 and 13). Using NCAA data and dividing the 119 FBS institutions represented in the presidential survey into deciles, the median budget for the top 12 institutions is

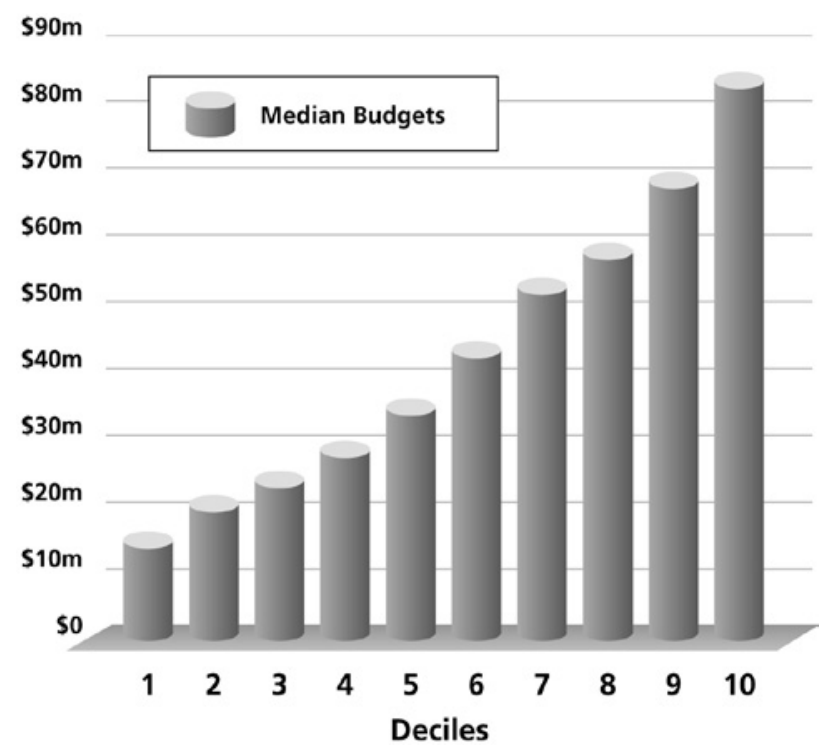

Figure 12 - This figure from the Knight Commission's College Sports 101 report illustrates the distribution of operating expense budgets for FBS athletic programs by decile. Note: To capture the differences in scale and scope of the 119 institutions in the FBS in 2006-07, they are divided into 10 groups of approximately 12 institutions each and ranked by total athletics operating expenses. This figure shows the median athletics operating budget for each of those deciles. This shows the class system emerging, separate from athletic conference and institutional philosophy. Data source: NCAA, 2006-07 fiscal year. 


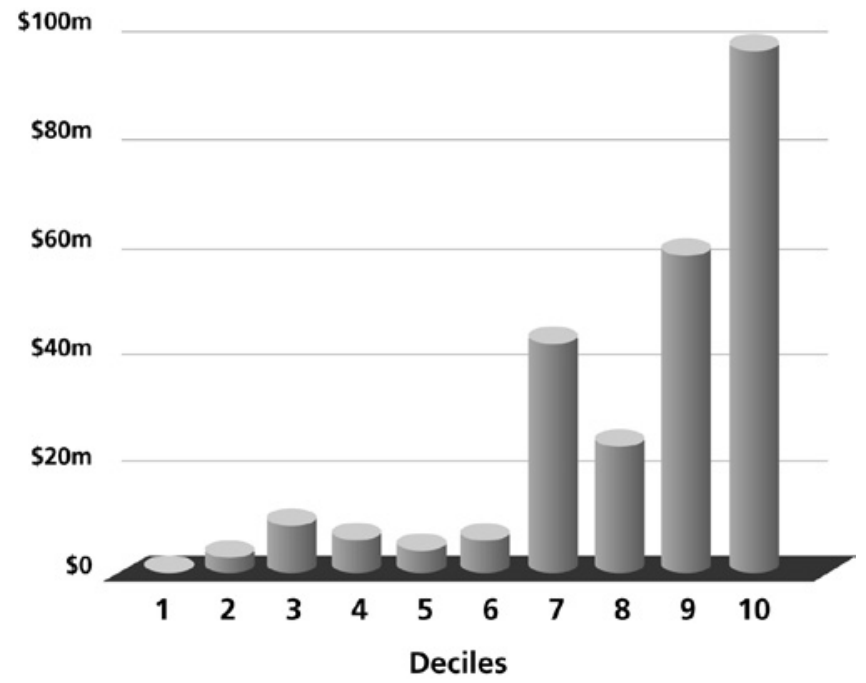

Figure 13 - This figure from the Knight Commission's College Sports 101 report shows the total athletics debts for FBS athletics programs. Note: This figure shows the medians for overall athletics debt for each decile grouped by operating expense budget as represented in Figure 12. Service payments on athletics debt are not included in the overall expense data. The $\$ 0$ value for decile 1 means that at least the bottom six schools in this decile grouping reported having no athletics debt. Data source: NCAA, 2006-07 fiscal year.

$\$ 83$ million and the median for those in the bottom tier is $\$ 14$ million (see Figure 12). Another significant difference is in total athletics debt where the top two deciles of institutions ranked by athletics expenditures show medians in athletics debt of $\$ 98$ million and $\$ 60$ million respectively, compared with the bottom two tiers that show median athletics debt of $\$ 3$ million and $\$ 0$ (see Figure 13).

Even some equity universities find themselves in the "have-nots" category, competing with institutions with "much broader and deeper resources to draw from due to their markets." Presidents of more wealthy equity institutions also recognized the challenges facing athletics programs with fewer financial resources:

Our athletic department has been self-sufficient for five years. But that clearly has to do with a successful football program and our stadium capacity. I don't know how a struggling, lower-conference school would deal with this. It must come out of education and general funds elsewhere.

Although the interviews revealed that many presidents were concerned about the inequities of the system, not all presidents found this situation troubling:

The stress of the economic environment will separate the haves and the havenots. There will be institutions that can't continue to compete at the Division I level. And that's not the end of the world. It'll be fine if Division I gets smaller and Division II gets larger. 
The potential result of institutions dropping out of the FBS due to their inability to sustain the financial commitment required was measured in the quantitative survey. Nearly $80 \%$ of all nonequity presidents supported giving priority to studying changes to reduce the level of financial commitment for FBS membership, while only $45 \%$ of those in equity conferences responded affirmatively to giving study priority to this area.

Despite the many differences in opinions on issues identified in the survey, 8 in 10 presidents $(83 \%)$ agreed that greater transparency of athletics operating and capital costs is needed.

\section{Implications of the Research}

The presidential research findings are eye-opening and raise concerns, but they reveal an environment ready for change. This assessment was strengthened at a September 28, 2009 meeting of the Division I-A Athletic Directors Association when 25 of the presidential survey questions were administered to the athletics directors in attendance using an audience response system. Two-thirds of all Division I-A athletics directors participated in this exercise and nearly $80 \%$ of the athletic directors agreed that given the current trends in revenues and expenses, athletics operations are not sustainable in their current form for FBS universities nationally. Seventy percent of them supported collective efforts to achieve financial stability for their programs.

The impact of the instability of the FBS as a whole was best described by Peter Likins, president emeritus at the University of Arizona and chair of the NCAA's 2006 Presidential Task Force on the Future of Division I Intercollegiate Athletics. At the Commission's October 27, 2009 meeting, Likins said that some institutions may believe they can sustain patterns of spending indefinitely but "the current system as a whole is going to break down and no institution can maintain its patterns if it loses the context in which it's competing athletically."

The big task as we move forward is to clearly define how to accomplish financial reforms in a system where there is great diversity among budgets, funding models, institutional practices, state legislation and other economic characteristics. But the goal of this reform effort is as clear as it was when James L. Knight, then chairman of the Knight Foundation, articulated the goal of the original Knight Commission: "We recognize that intercollegiate athletics have a legitimate and proper role to play in college and university life. Our interest is not to abolish that role but to preserve it by putting it back in perspective" (Knight Commission on Intercollegiate Athletics, 1991).

The Commission believes the first step among the actions that are necessary to put the financial model back into perspective involves true transparency around athletics spending - a recommendation around which the greatest consensus among presidents $(83 \%)$ emerged from the survey. Academic reform hit a tipping point when graduation rates were first shared publicly, and the same can hold true with greater transparency around financial data in intercollegiate athletics and its growth and relationship to educational budgets.

The NCAA has done much good work over the past five years to improve the accuracy of financial data being collected by institutions and organizing those data in a useful financial management database accessible to all presidents. This work provides a solid foundation from which to build. 
The goal also must not be to simply find ways to justify or sustain trends that we believe are unhealthy for our institutions and for the FBS as a whole. We cannot maintain the status quo. The presidential survey has amplified a call for change and identified various strategies and policy changes that should be considered by the NCAA Board of Directors. Indeed, one of the most important findings of this examination is in revealing an environment that is ready for change.

\section{Note}

1. R. Gerald Turner, Ph.D., Co-Chairman, Knight Commission on Intercollegiate Athletics, and President, Southern Methodist University, assisted the authors in presenting this paper at the Colloquium.

\section{Acknowledgments}

The authors wish to thank the John S. and James L. Knight Foundation for funding the research presented in this paper; Alberto Ibargüen and Paula Ellis with Knight Foundation for their support of the Knight Commission's goals; William E. "Brit" Kirwan and R. Gerald Turner for their leadership as co-chairmen of the Knight Commission; all Knight Commission members for their thoughtful discussion and input that shaped these research projects; Dennis Kramer and Scott Hirko for their research assistance and for editing this paper; Welch Suggs and Andrew Zimbalist for their assistance with the Knight Commission's College Sports 101 data and for serving on the advisory group for the presidential survey; Janet Lawrence, Ted Leland, Jeff Orleans, and Jane Wellman for serving on the advisory group for the presidential survey; Todd Petr and the NCAA research staff for their assistance with compiling NCAA financial data for use in the presidential survey and College Sports 101; the 95 university presidents who invested their time in participating in this research; and the athletic directors who participated in the Knight Commission's survey conducted at the 2009 Division I-A Athletic Directors meeting.

\section{References}

Brand, M. (2008). NCAA President's Report. Indianapolis, IN: The National Collegiate Athletic Association.

Brand, M. (2009). Proceedings from the 2009 NCAA Convention: State of the Association Address. Retrieved January 2, 2010 from http://www.ncaa.org/ wps/portal/ncaahome?WCM_GLOBAL_CONTEXT=/ncaa/ncaa/ncaa+news/ ncaa+news+online/2009/association-wide/the+2009+ncaa+state+of+the+association +speech+-+1-15-09+-+ncaa+news

Fulks, D. (2009). Revenue / Expenses: 2004-08 NCAA Revenues and Expenses of Division I Intercollegiate Athletics Programs Report, Indianapolis, IN: The National Collegiate Athletic. Retrieved January 21, 2010 retrieved from http://www.ncaapublications.com/ ProductsDetailView.aspx?sku=RE09

Knight Commission on Intercollegiate Athletics. (1991). Keeping Faith with the StudentAthlete: A New Model for Intercollegiate Athletics. Miami, FL: The John L. \& James S. Knight Foundation.

Knight Commission on Intercollegiate Athletics. (2009). College Sports 101. Miami, FL: The John L. \& James S. Knight Foundation. Retrieved January 1, 2010 from http:// collegesports101.knightcommission.org 